\title{
Das Palmenhaus wird 150!
}

In diesem Jahr feiern wir das 150-jährige Bestehen des Palmenhauses. Über dem Eingang zu den beiden Galerien ist am Palmenhaus die Jahreszahl der Fertigstellung (1869) gut zu erkennen. Im Winter 1869/70 richtete der Gartenbauinspektor FERDINAND Heiss mit Unterstützung des Gartendirektors Karl Thelemann das Palmenhaus ein. Aber erst am 18. März 1871 wurde der Palmengarten offiziell eröffnet. Das Palmenhaus ist trotz der Luftangriffe auf Frankfurt im zweiten Weltkrieg weitestgehend im Originalzustand erhalten. Es wurde 1998/99 grundsaniert. Die folgenden Seiten zeigen aktuelle Ansichten des Palmenhauses sowie Palmenhausmotive von historischen Ansichtskarten aus der ersten Hälfte des 20. Jahrhunderts. (Alle Fotos: Hilke Steinecke, Ansichtskarten: Sammlung Hilke Steinecke)

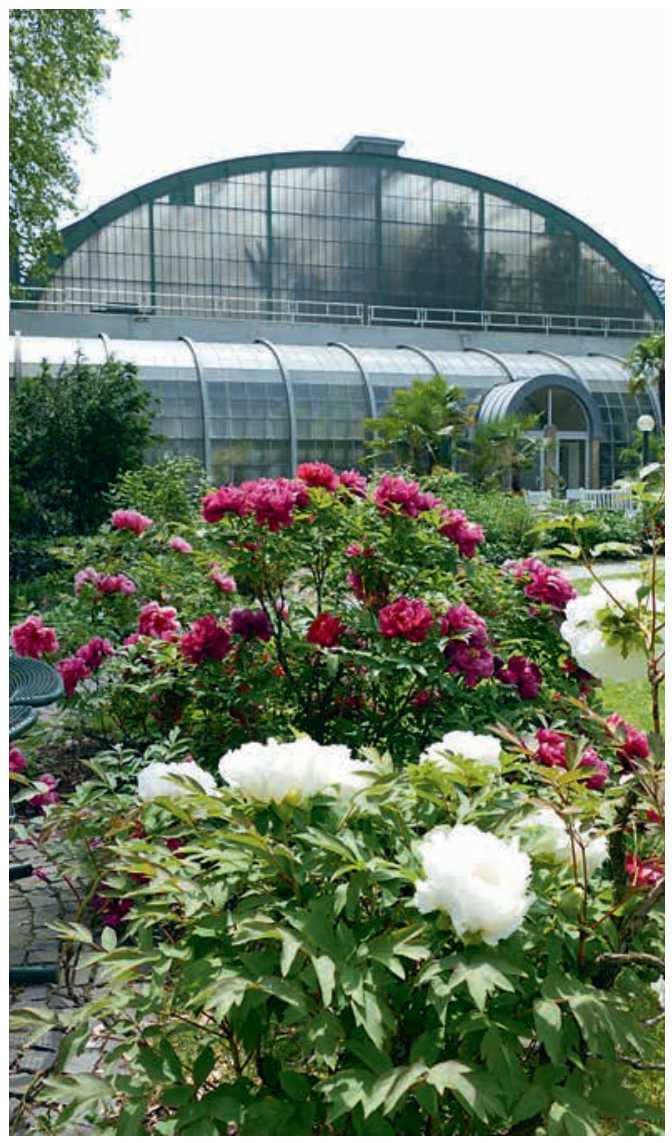

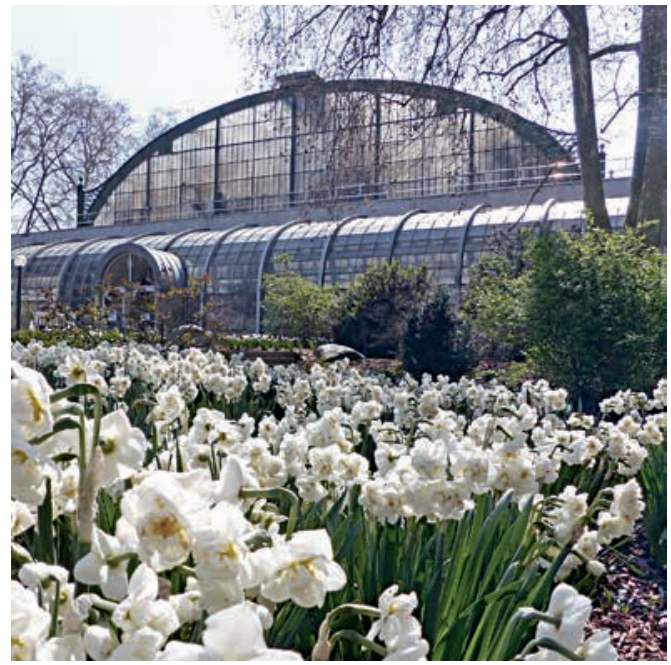
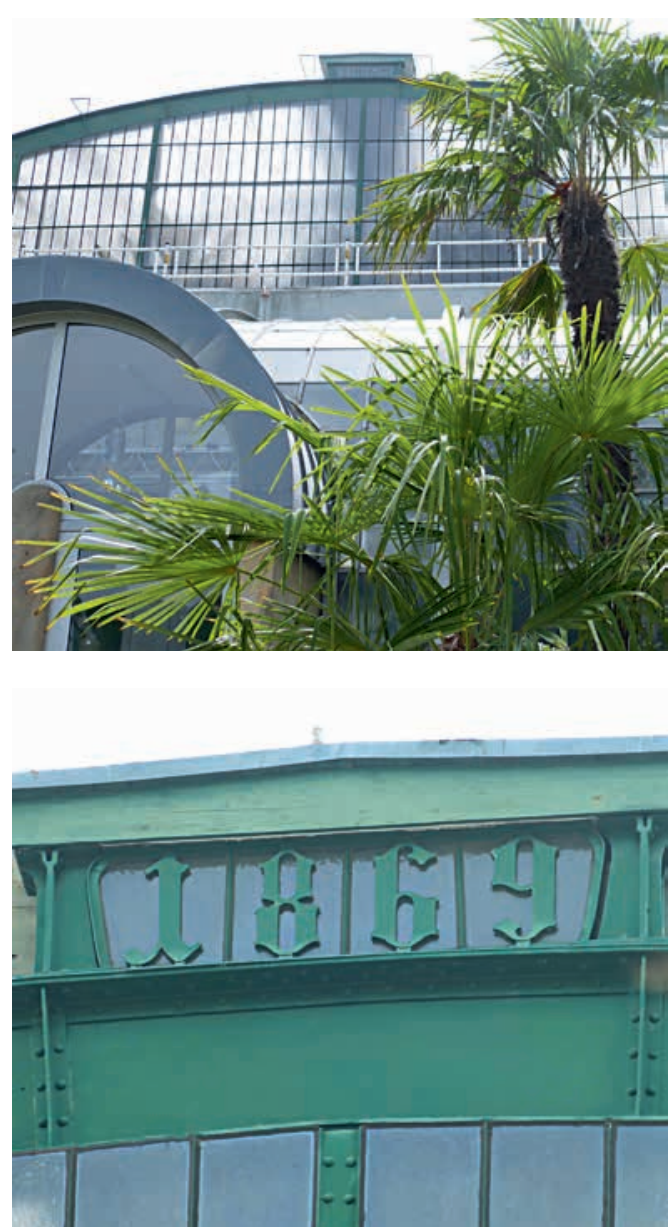

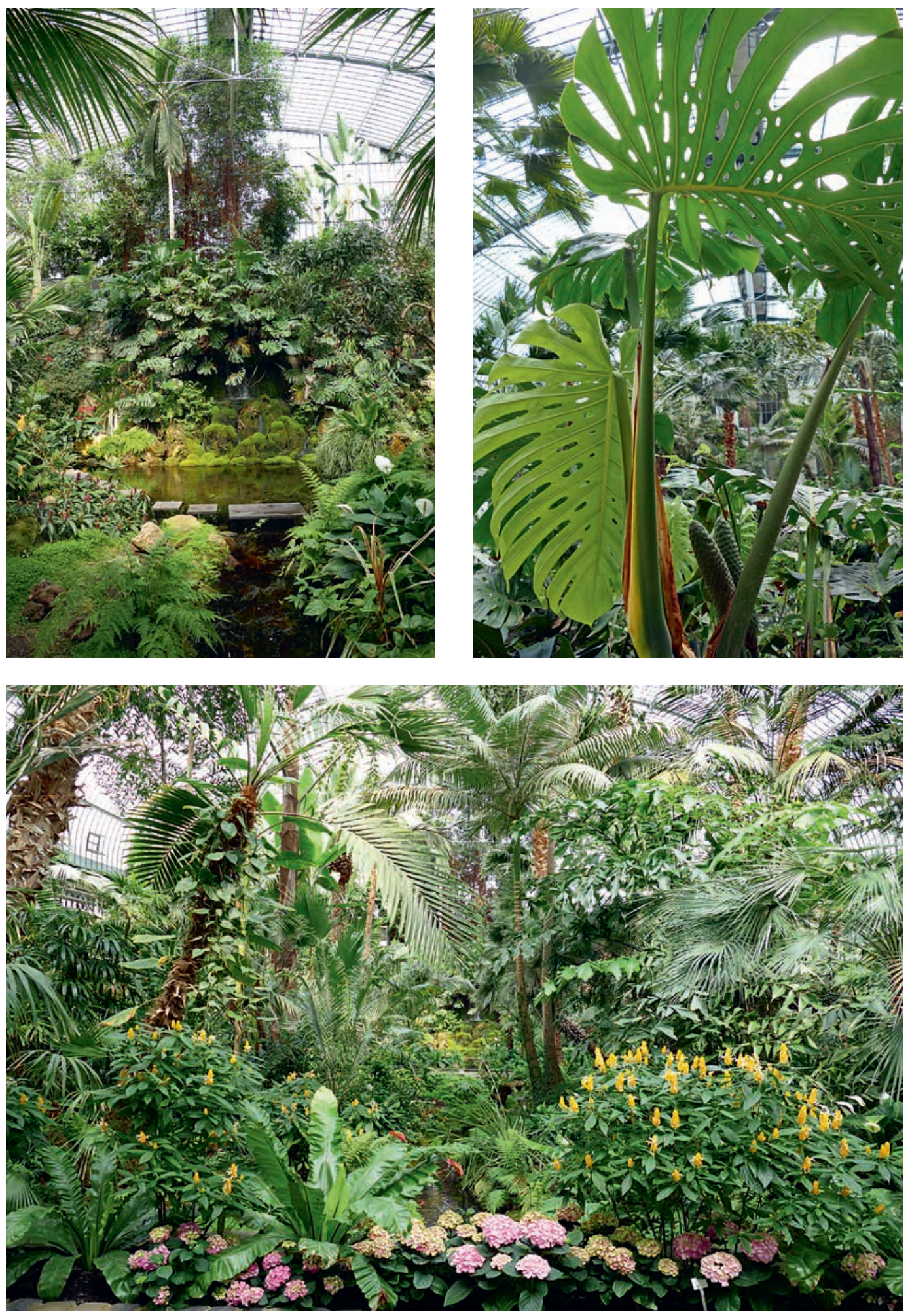

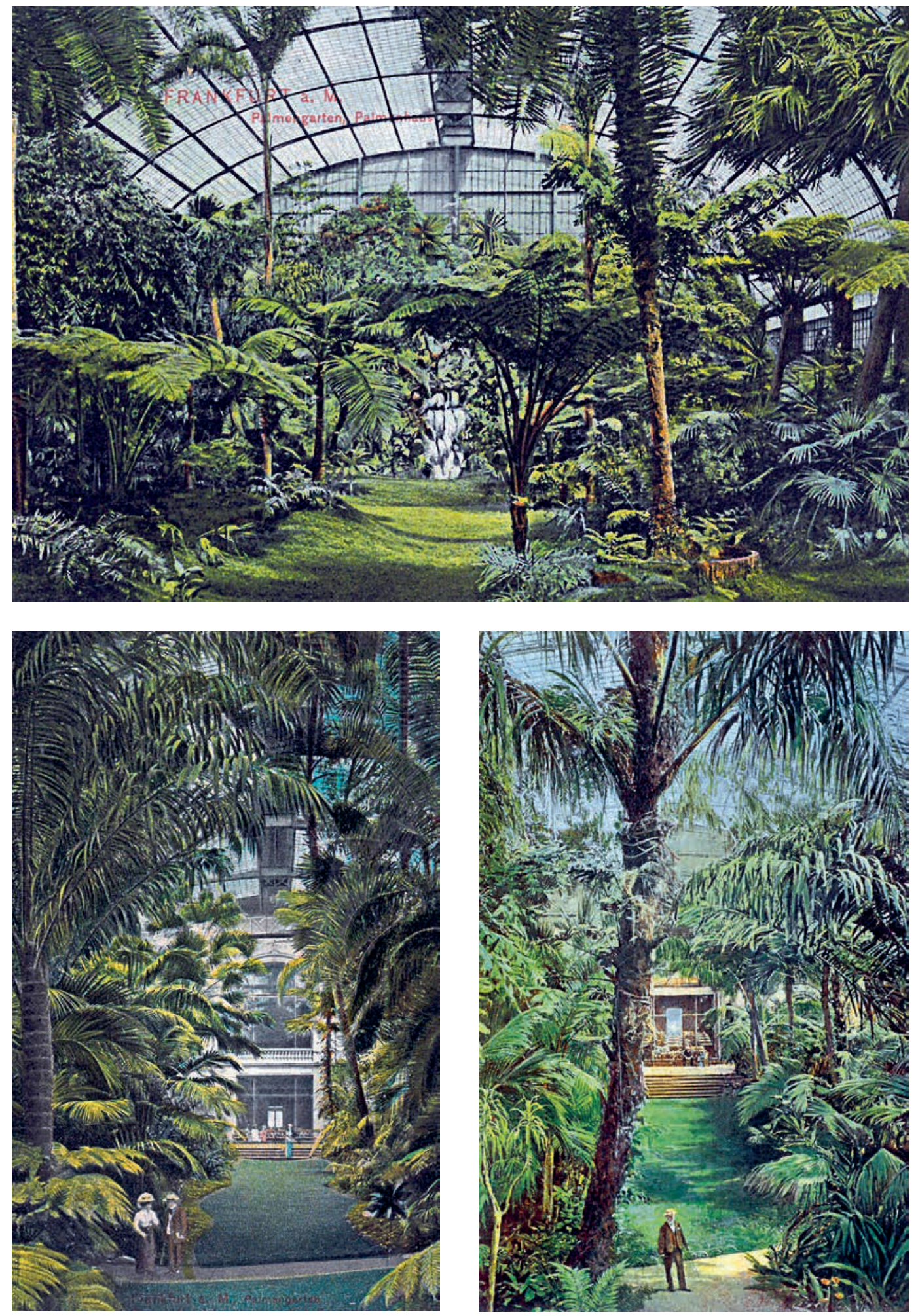

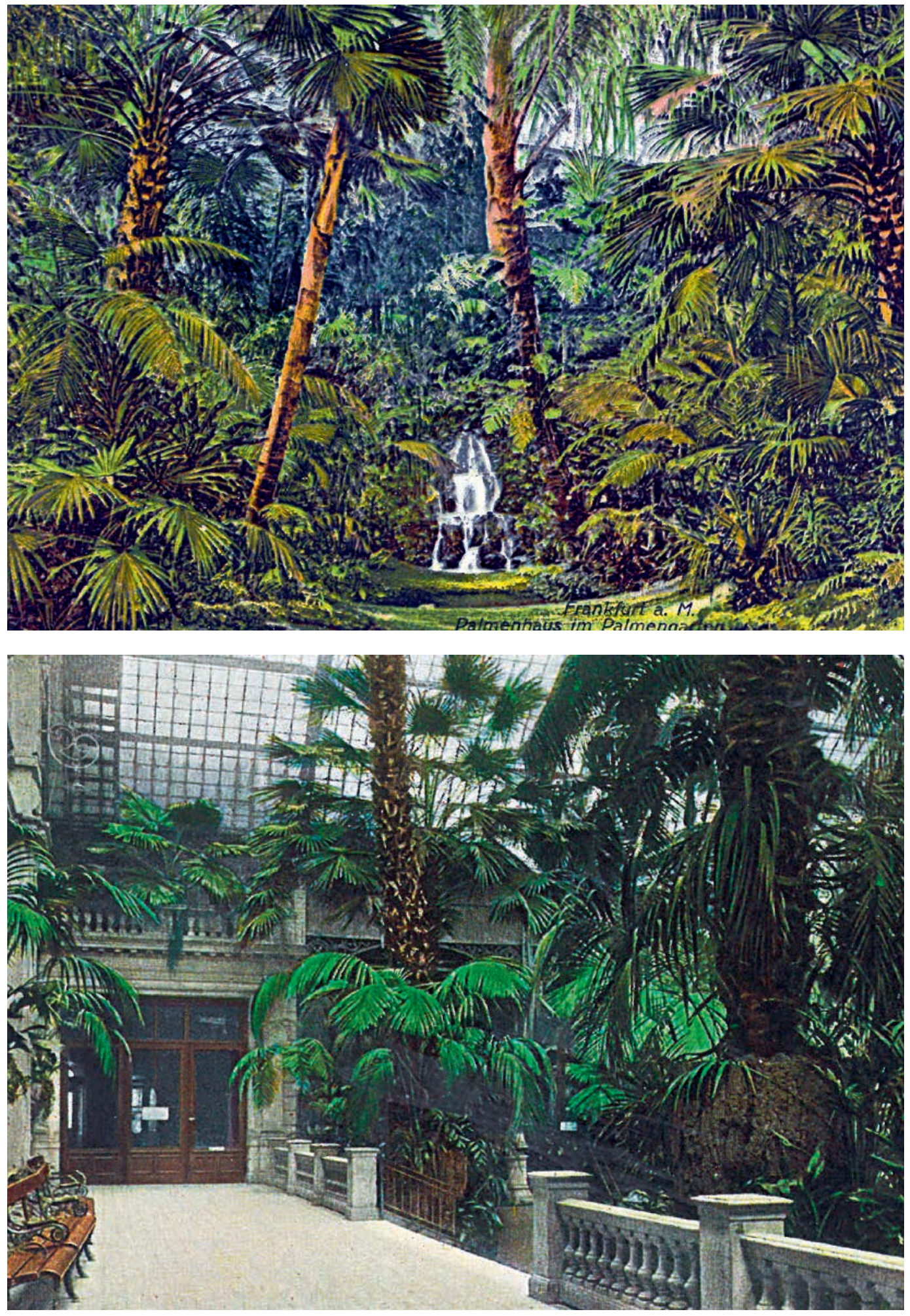

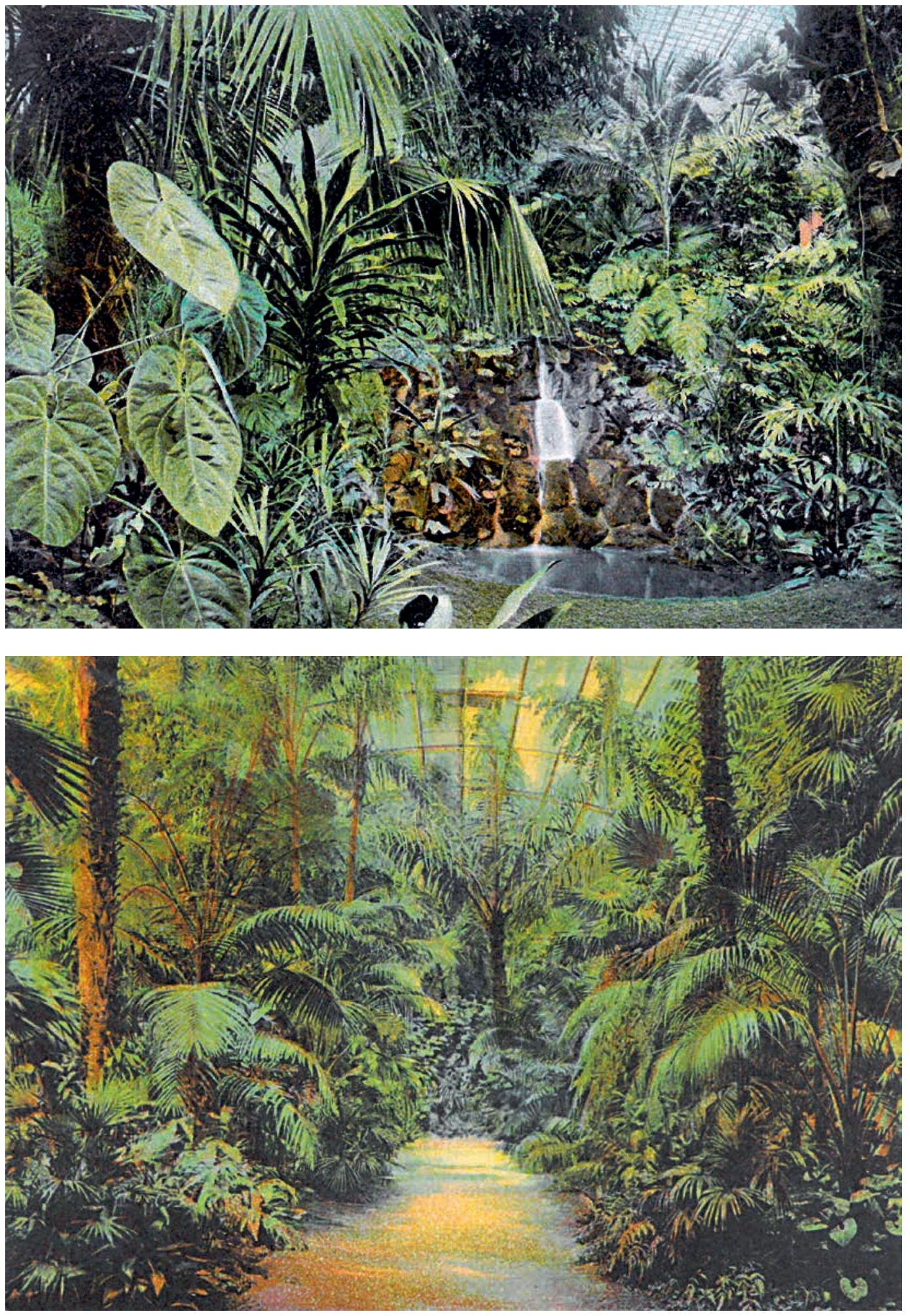


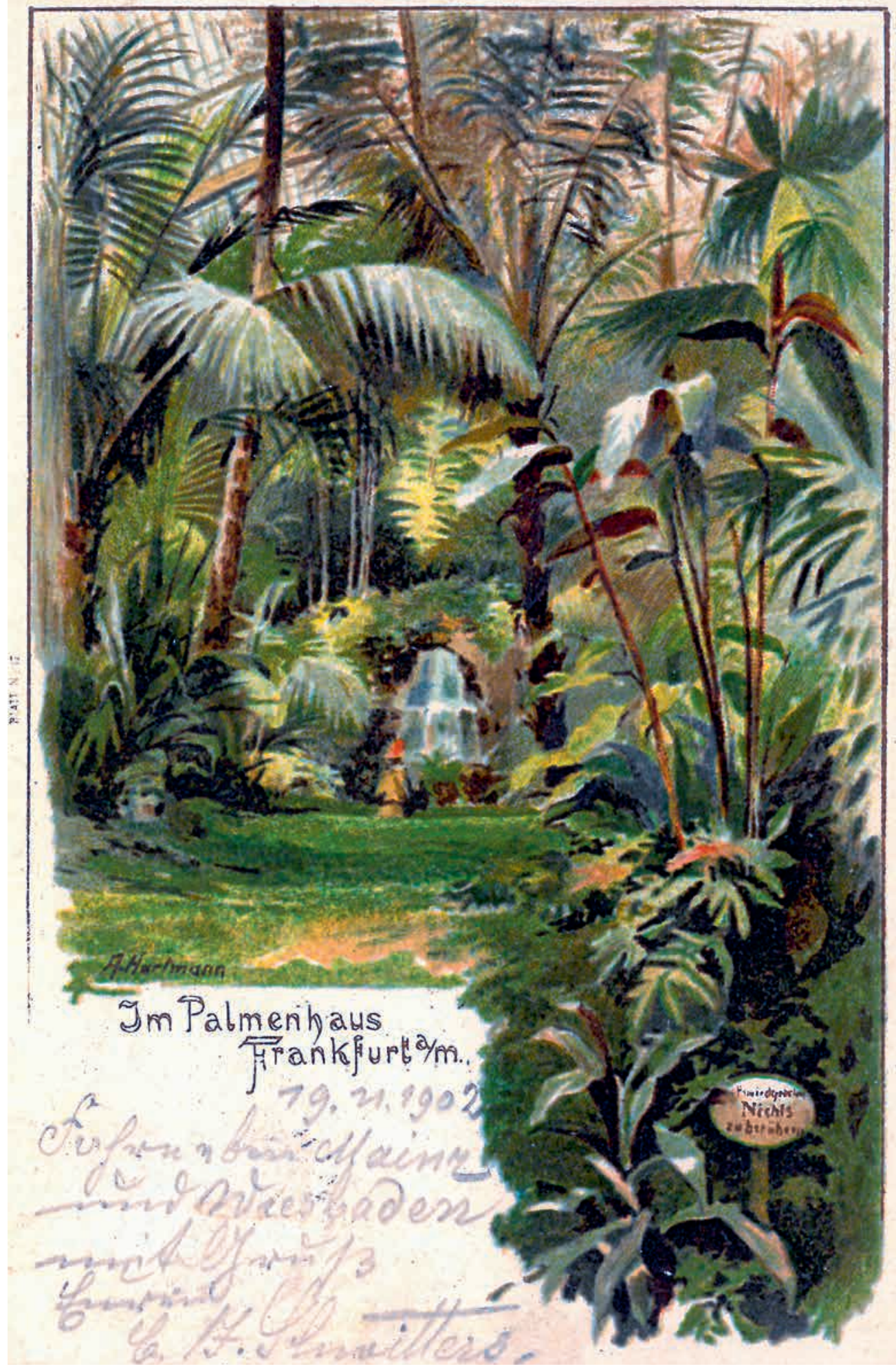

